\title{
PERCEPÇÃO E EXPERIÊNCIA NA CRIAÇÃO POÉTICA ${ }^{1}$
}

\section{PERCEPTION AND EXPERIENCE IN THE POETIC CREATION}

\author{
Márcio THAMOS ${ }^{2}$ \\ UNESP - Universidade Estadual Paulista
}

RESUMO: A linguagem artística está profundamente relacionada à capacidade de imaginação do espírito humano. A experiência poética funda-se na percepção física da existência. O poeta busca dar a ver, através de imagens, aquilo que deseja exprimir e tende a valer-se da palavra como uma coisa em si.

PALAVRAS-CHAVE: Poesia; Percepção Sensorial; Poeticidade; Materialidade da Palavra.

ABSTRACT: The artistic language is deeply related to the ability of imagination of the human spirit. The poetic experience is based on the perception of physical existence. The poet tries to show through images what he wishes to express and his tendency is to deal with words as a concrete thing.

KEYWORDS: Poetry; Sensory Perception; Materiality of the Word.

[...] por causa de um verso é preciso ver muitas cidades, pessoas e coisas, é preciso conhecer bichos, é preciso sentir como voam os pássaros, $e$ saber com que gestos flores diminutas se abrem ao amanhecer.

Rainer Maria Rilke (1979, p. 14).

Ter um corpo é como fazer poemas. Adélia Prado (1991, p. 392).

Na época em que morava na França, Naná Vasconcelos, percussionista de renome mundial, recebeu um convite do psiquiatra Tony Lane para desenvolver um trabalho com crianças excepcionais. A música era associada ao tratamento dos estímulos da criança, e

1Texto apresentado em 4 de setembro de 2010, durante o Seminário de Semiótica "Ignacio Vive: 10 anos de Grupo CASA", como singela homenagem ao Professor Ignacio Assis Silva.

2Professor da Área de Latim (língua e literatura) do Departamento de Linguística - Faculdade de Ciências e Letras, UNESP, Campus de Araraquara - e coordenador do Grupo Linceu: Visões da Antiguidade Clássica/CNPq. 
Naná improvisava intuitivamente, de acordo com a reação desta. Ele conta que foi então que sentiu a necessidade de criar a "percussão corporal", pois, como explica,

Tudo que é feito com o corpo a gente não esquece. Se você fizer o seu corpo aprender a andar de bicicleta, daqui a vinte anos você vai tentar andar e consegue. Pode titubear, mas consegue. Agora, se você ler num livro como andar de bicicleta, depois de um tempo você esquece, daí a importância do aprendizado do corpo e não só da cabeça. (1997, p. 21).

Esse depoimento informal do músico brasileiro serve para ilustrar um dado importante que se deseja aqui ressaltar: uma experiência autêntica é, antes de tudo, apreendida pelos sentidos, isto é, vivenciada através do corpo. São eles, os cinco canais que ligam o homem à realidade, que, em última instância (ou, nesse caso, talvez se devesse falar em "primeira"), permitem todo conhecimento. Os poetas parecem estar convencidos, como Joseph Brodsky (1994, p. 172), de que "Quaisquer noções que tenhamos acerca de qualquer coisa baseiam-se na experiência". Também os grandes prosadores costumam dar testemunho de sua crença em que toda elaboração do espírito criativo necessita de um mínimo de base empírica. Luigi Pirandello ([19--], p. 102), através das elucubrações d'O Falecido Matias Pascal, formula a seguinte ideia:

Nada se inventa, é verdade, que não possua alguma raiz, mais ou menos profunda, na realidade; e até as coisas mais estranhas podem ser verdadeiras; aliás, nenhuma fantasia consegue conceber certas loucuras, determinadas aventuras inverossímeis que se desencadeiam e que explodem, partindo do seio tumultuoso da vida; ainda assim, como e quanto a fantasia parece diferente das invenções que nós podemos extrair, com base na realidade viva e palpitante! De quantas coisas substanciais, miúdas e inimagináveis, precisa revestir-se a nossa invenção, para transformar-se naquela mesma realidade de que foi extraída, ou em que esteve baseada; de quantos fios ela precisa, para se realinhavar na complicadíssima trama da vida - fios que nós cortamos, para fazer com que a fantasia se transforme numa coisa em si!

Na Poética, Aristóteles (1952, p. 42) considera que "la poésie est-elle plus philosophique et d'un caractère plus élevé que l'histoire; car la poésie raconte plutôt le général, l'histoire le particulier". Essa afirmação do antigo filósofo procura ressaltar o aspecto indutivo do conhecimento poético, que seria capaz de revelar o geral no particular. Deve-se, com isso, compreender que, apesar de ser uma experiência de caráter particular, a poesia atinge uma dimensão universal na medida em que expressa aquilo que pode ser vivenciado pelo espírito humano sem esgotar-se em circunscrições determinadas do espaço-tempo - e é isso que a torna filosófica.

Para Octavio Paz (1990, p. 192-193), a poesia

No es una explicación de nuestra condición, sino una experiencia en la que nuestra condición, ella misma, se revela o manifiesta. Y por eso también está indisolublemente ligada a un decir concreto sobre esto o aquello. La experiencia poética - original o derivada de la lectura - no nos enseña ni nos dice nada sobre la libertad: es la libertad misma desplegándose para alcanzar algo y así realizar, por un instante, al hombre. La infinita diversidad de poemas que registra la historia procede del carácter concreto de la experiencia poética, que es experiencia de esto y aquello; pero esta 
diversidad también es unidad, porque en todos esos y aquellos se hace presente la condición humana.

A condição humana é primeiramente a do embate com a realidade física do mundo; toda possibilidade de conhecimento advém desse fato inexorável. Portanto a revelação poética dessa condição não se pode dar sem a vívida experiência das coisas. A poesia é uma manifestação da essência do homem, de sua consciência como ser; mas essa consciência não se pode desenvolver - na verdade, nem sequer existir - sem a percepção do que está fora dela mesma.

A experiência poética está fundada na percepção concreta da existência. Viver é mover-se num mundo repleto de objetos particulares - isto é, de seres outros, com sua constituição própria - e interagir com eles em condições e em situações particulares todo o tempo. Viver com intensidade é redescobrir as coisas a cada dia, descobrindo-se a si mesmo continuamente através delas; é chegar a suprimir talvez esse "através" e ser capaz de vislumbrar uma contiguidade universal em que noções como sujeito e objeto se conjuguem e se completem. A poesia nos oferece essa possibilidade. Ela testa-nos os sentidos, excita-os, causa impressões novas que, ao menos por um instante, despertam-nos da inércia letárgica do dia a dia e provam que estamos vivos. Ela pode mesmo nos levar até o limite daquele vislumbre ao provocar incessantemente suas analogias sinestésicas. O poema é o testemunho da sensibilidade ávida, da percepção ativa e criativa, que não se deixa embotar pela aparente monotonia das coisas. Se escrevesse seu Discurso sobre o método, o poeta, parodiando o filósofo, diria: "Sinto, logo existo."

A realidade nos chega sempre pelos sentidos. É só através do corpo físico que se vai aos poucos tomando consciência do eu. A percepção é o que torna o homem um ser em si e no mundo e o que lhe permite expandir a própria consciência. Se se acredita que a arte seja, a princípio, a expressão mesma da condição humana revelada a partir de uma experiência particular, é compreensível que todo artista sinta necessidade de trabalhar com algo mais ou menos palpável, a matéria com que forjará sua obra.

Conforme Thomas Ramson Giles (1979, p. 176),

A expressão estética não é um ato do espírito "puro", mas um processo de descoberta progressiva, através da manipulação de uma matéria real. Portanto, a expressão artística só será completada quando se manifestar como um todo em uma matéria. Esse todo é a obra de arte.

O poeta, o artista literário, procura na palavra esse elemento material, concreto, de que necessita; fala sempre através de imagens e tende a valer-se da palavra como uma coisa em si. Em um breve trecho de uma de suas entrevistas, João Cabral de Melo Neto (1989, p. 26) nos dá uma ideia de como o poeta procura lidar com a face mais sensorial das palavras:

A palavra concreta é a palavra que você entende pelos sentidos. E a palavra abstrata é a palavra que você atinge pela inteligência. Eu tenho a impressão de que a poesia é uma linguagem que se dirige à inteligência, mas através dos sentidos. Uma palavra concreta é muito mais sensorial que uma palavra abstrata. Se eu disser "tristeza", cada um de nós aqui tem uma ideia de "tristeza". Se eu disser "Coca-cola", "copo de coca-cola" ninguém vai pensar que eu estou falando em "xícara de chá". Eu tenho a impressão de que é muito mais fácil eu dar a ver com palavras concretas que se dirigem aos sentidos do que usando palavras abstratas. 
A espontaneidade transparente na fala do poeta - o qual com certeza não pretendia fazer propaganda de refrigerante, mas apenas, pode-se imaginar, aproveitou um exemplo que tinha literalmente à mão - reforça a naturalidade com que encara e utiliza o recurso aí exposto de maneira simples e imediata.

As palavras de sentido concreto são mais particularizantes, figurativas em oposição às de sentido abstrato, mais generalizantes, temáticas; por isso o poeta privilegia as primeiras. A palavra concreta, ao evocar psiquicamente uma imagem, atinge, de forma mais direta, a inteligência através dos sentidos. Mas a poesia precisa de mais concretude. O poeta, de certo modo, ressente-se da arbitrariedade do signo e, inconformado, tenta negá-la. Para Roman Jakobson (1978, p. 177), quando a poeticidade, a função poética em caráter dominante, manifesta-se em um texto,

A palavra é então experimentada como palavra e não como simples substituto do objeto nomeado, nem como explosão de emoção. As palavras e sua sintaxe, sua significação, sua forma externa e interna não são então indícios indiferentes da realidade, mas possuem o seu próprio peso e o seu próprio valor.

$\mathrm{Na}$ linguagem não literária, as palavras remetem a alguma coisa fora delas mesmas quase de imediato, sem terem sua própria presença pressentida. Nesse caso, o valor das palavras reside exclusivamente na possibilidade de serem substituídas pela ideia que carregam; ao serem compreendidas - ou "ao dizerem o que têm a dizer" -, é natural que sejam em si mesmas descartadas. Na poesia, isto é, numa obra literária em que se manifesta a poeticidade, as palavras não deixam de representar algo, mas são percebidas, ao mesmo tempo, como um outro algo cuja presença, além de possibilitar a mensagem, confere-lhe um interesse estético peculiar. $\mathrm{O}$ artista literário agrega um outro valor à mensagem, não alheio a esta, que faz do poema um ato de linguagem insubstituível, ao evocar a palavra em sua plenitude, tornando-a necessária em si mesma. Talvez não seja demais citar aqui a célebre frase que Paul Valéry (1991, p. 208) conta ter ouvido várias vezes do pintor Degas. Quando este, um dia, queixara-se a Mallarmé da dificuldade que encontrava em fazer versos, apesar de não lhe faltarem ideias, o poeta lhe teria respondido: "Absolutamente não é com ideias, meu caro Degas, que se fazem os versos. É com palavras".

Sendo o elemento fônico da linguagem a substância mais palpável de que dispõe, o poeta naturalmente tende a dispensar-lhe grande atenção. A plasticidade da palavra tem sempre uma enorme relevância para o trabalho do artista literário. A palavra poética nunca deixa de ser uma coisa em si, e o sentido do poema estará sempre impregnado pelas sugestões da materialidade da substância que o compõe, de acordo com o contexto em que se insere.

Lembre-se ainda outra breve passagem de El arco y la lyra, em que Octavio Paz (1990, p. 107) chama a atenção para o fato de que "Un paisaje de Góngora no es lo mismo que un paisaje natural, pero ambos poseen realidad y consistencia, aunque vivan en esferas distintas. Son dos órdenes de realidades paralelas y autónomas". Com efeito, não é de outro modo que se constitui o texto poético. A palavra e aquilo que ela refere possuem cada um a sua realidade própria. A palavra significa uma coisa ao mesmo tempo em que é outra. Entre o significar e o ser, há uma distância intransponível que o poeta teima em tentar desfazer. Mas, se houvesse um poema cujas palavras, uma a uma, pudessem-se trocar pelas coisas que designam, quando muito, outro poema seria criado, e não o mesmo. A materialidade da palavra, seu aspecto mais palpável, aquilo que a torna insubstituível num texto literário é 
CASA, Vol.8 n.2, dezembro de 2010

imprescindível na construção do efeito de sentido poético. Na materialidade da palavra, o poeta encontra novas possibilidades para a formalização do(s) sentido(s).

\section{Referências bibliográficas}

ARISTOTE. Poétique. $2^{\mathrm{e}}$ éd. Texte établi et traduit par J. Hardy. Paris: Les Belles Lettres , 1952.

BRODSKY, J. Menos que um. Tradução de S. Flaksman. São Paulo: Companhia das Letras, 1994.

GILES, Th. R. Introdução à filosofia. 3. ed. São Paulo: Epu; Edusp, 1979.

JAKOBSON, R. O que é a poesia? In: Toledo, D. (Org.). Círculo linguístico de Praga: estruturalismo e semiologia. Trad. Z. de Faria, R. Toledo e D. Toledo. Porto Alegre: Globo, 1978, p. 167-180.

LIMA, A. D. Uma estranha língua? São Paulo: Edunesp, 1995.

MELO NETO, J. C. de. (Entrevista). Revista 34 letras, n. 3. Rio de Janeiro, 1989, p. 8-45.

PAZ, O. El arco y la lira. 3. ed. México: Fondo de Cultura Económica, 1990.

PRADO, A. Poesia reunida. São Paulo: Siciliano, 1991.

PIRANDELlO, L. O Falecido Matias Pascal. Trad. R. de Polillo. São Paulo: Livraria Martins, [19--].

RILKE, R. M. Os cadernos de Malte Laurids Brigge. Trad. de L. Luft. Rio de Janeiro: Nova Fronteira, 1979.

VALÉRY, P. Poesia e pensamento abstrato. In: . Variedades. Trad. M. M. de Siqueira. São Paulo: Iluminuras, 1991, p. 201-220.

VASCONCELOS, N. Berimbau bateu, camará! Salve Naná! (artigo de D. A. Neves a partir de entrevista). Modern drummer Brasil (publicação da Bass Art Editorial Ltda.). São Paulo, n. 12, 1997, p. 18-27. 